Report

\title{
Estimation of Concentrations of Antifungal Agents Allowed as Food Additives in Foods and Their Daily Intake Based on Official Inspection Results in Japan in Fiscal Year 1998*
}

(Received July 16, 2001)

\author{
Hajimu Ishiwata ${ }^{* 1, * 2, \dagger}$, Yukiko AbE*1, Hiroki Kubota*1, Yoko KaWasaki*1, \\ Yuiko Takeda*1, Tamio Maitani*1, Motohiro Nishijima*3 \\ and Yoshinobu FukASAwa ${ }^{*}$
}

\begin{abstract}
( ${ }^{* 1}$ National Institute of Health Sciences: 1-18-1, Kamiyoga, Setagaya-ku, Tokyo 158-8501, Japan; ${ }^{* 2}$ National Institute of Health Sciences, Osaka Branch: 1-1-43, Hoenzaka, Chuo-ku, Osaka 540-0006, Japan; *33Faculty of Human Life Sciences, Jissen Women's University: 4-1-1, Osakaue, Hino-shi, Tokyo 191-8501, Japan; ${ }^{* 4}$ Yamanashi Institute of Public Health: 1-7-31, Fujimi, Kofu-shi, Yamanashi 400-0027, Japan; ${ }^{\dagger}$ Corresponding author)
\end{abstract}

Key words: antifungal agent; concentration in food; daily intake; diphenyl; imazalil; $o$-phenylphenol; thiabendazole; official inspection

The mean concentrations and daily intake of four antifungal agents were estimated based on the results of an analysis of 7,005 samples of food obtained in official inspections by Japanese local governments in fiscal year 1998. The mean concentration of diphenyl was $0.0004 \%$ of the allowable limit, and those of imazalil, $o$-phenylphenol, and thiabendazole were 14.0\%, 3.5\%, and $5.7 \%$, respectively. The daily intakes of these antifungal agents per person, estimated from their concentrations and the daily consumption of the foods, were $0.000326,1.89,11.5$, and $23.3 \mu \mathrm{g}$, respectively, and assuming a body weight of $50 \mathrm{~kg}$, the amounts of these antifungal agents consumed were $0.000013 \%, 0.15 \%, 0.12 \%$, and $0.47 \%$ of the acceptable daily intake, respectively. These values are similar to the values obtained on the basis of the results of the official inspection in fiscal years 1994 and 1996, except that the amount of diphenyl is much lower (1/100).

\section{Introduction}

Estimates of the daily intake of 16 food additives based on the results of official inspections in Japan in fiscal year 1996 have been reported ${ }^{1-4)}$. We repeated the same surveillance study on the same 16 food additives based on the results of official inspections in fiscal year 1998 and reported estimates of the daily intake of preservatives $^{5)}$ in fiscal year 1998. In the present study, we estimated the mean concentrations of the four antifungal agents allowed as food additives in Japan, diphenyl, imazalil, o-phenylphenol, and thiabendazole, and deduced the daily intakes of these antifungal agents per person from the mean concentration and amounts of foods consumed.

\section{Methods}

The methods used were the same as those previously

* Concentration of Food Additives in Foods and the Daily Intake in Japan (Report No. 10) [Report No. 9 was entitled "Estimation of Preservative Concentrations in Foods and Their Daily Intake Based on Official Inspection Results in Japan in Fiscal Year 1998", published in this Journal, 42, 404-412 (2001).] described $^{2), 5)}$, but this time the results of new official inspections performed in fiscal year 1998 were used.

1. Investigation methods and items studied

a) Questionnaire

The Division of Food Chemistry, Ministry of Health and Welfare of Japan sent a questionnaire ${ }^{6)}$ concerning the results of official inspections for food additives from April 1, 1998 to March 31, 1999 (Japanese fiscal year 1998) to all 114 local governments that are obliged to establish public health centers by the Regional Public Health Law.

b) Items queried

The following antifungal agents were investigated in this study: diphenyl, imazalil, o-phenylphenol (ophenylphenol and sodium $o$-phenylphenol), and thiabendazole. Sodium $o$-phenylphenol is also permitted to be used as an antifungal agent in Japan, but it is regulated in terms of the concentration of $o$-phenylphenol in accordance with Japan's Specifications and Standards for Food Additives ${ }^{7}$. The names of both imported and domestic foods, the numbers of food samples inspected, the numbers of samples in which these antifungal agents were detected, the maximum, minimum, and 
mean concentrations in the samples in which they were detected, and the detection limit of the analysis for each antifungal agent were recorded.

c) Sampling of foods and methods of determining antifungal agents

In accordance with the annual program of each local government, samples were chosen by food inspectors in markets or factories manufacturing food products. Basically, the GC method was used for the determination of diphenyl, o-phenylphenol, and thiabendazole ${ }^{8)}$, and the HPLC method for imazali1 ${ }^{9)}$, as followed by the Guide for Food Inspection by the Ministry of Health and Welfare.

\section{Analyses of reports from the local governments}

Data sent back from the local governments were classified according to the categories of foods in Japan's Specifications and Standards for Food Additives ${ }^{7)}$. Foods in which these compounds are not allowed to be used were categorized according to the Guide for Categorization of Food ${ }^{10)}$. As in the previous papers ${ }^{1), 2)}$, when concentrations of these antifungal agents were below the detection limits, they were regarded as $0 \mathrm{mg} /$ $\mathrm{kg}$. Some local governments did not break down the allowable citrus into subcategories but categorized them as "allowable citrus" or "citrus" because the residual concentration limits of antifungal agents in allowable citrus or citrus are the same. In these cases, the results were categorized as allowable citrus for diphenyl or citrus for other antifungal agents.

\section{Calculations and estimation of daily intake}

The daily intake of each antifungal agent per person was estimated based on the mean concentrations of these agents in all foods (including nonpermissible foods) obtained in the present study, and daily food consumption levels ${ }^{11)}$ reviewed in 2000 . When the consumption level of a food was unknown, $0.01 \mathrm{~g}$ was assumed to be the daily consumption per person, as described in the previous papers ${ }^{5)}$.

\section{Results}

\section{Questionnaire return and number of samples}

Replies were obtained from 108 of the 114 local governments (94.7\%), representing most of Japan. Antifungal agents were inspected by 77 governments (71.3\% of the 108 local governments which replied). Inspection was performed for diphenyl by 71 local governments, for imazalil by 67 local governments, for o-phenylphenol by 72 local governments, and for thiabendazole by 69 local governments. The total number of food samples inspected for these antifungal agents was 7,005 , of which 6,421 (91.7\% of total samples) were samples of imported food (Table 1). The total sample number in 1998 was 1.1 times of that in $1996^{2)}$. The results obtained in the present study were therefore considered to be highly reliable, since inspection results were received from more than half of the local governments in Japan and large numbers of samples were
Table 1. Number of Local Governments That Performed Inspections for Antifungal Agents and the Number of Food Samples Inspected

\begin{tabular}{lcccc}
\hline \hline \multirow{2}{*}{ Antifungal agent } & \multirow{2}{*}{$\begin{array}{c}\text { Number of } \\
\text { local gov- } \\
\text { ernments }\end{array}$} & \multicolumn{3}{c}{ Number of samples } \\
\cline { 3 - 5 } & 71 & 81 & 1,400 & 1,481 \\
\hline Diphenyl & 67 & 170 & 1,711 & 1,881 \\
Imazalil & 72 & 124 & 1,760 & 1,884 \\
o-Phenylphenol & 69 & 209 & 1,550 & 1,759 \\
Thiabendazole & 69 & 584 & 6,421 & 7,005 \\
\hline Total & 77 & & &
\end{tabular}

tested.

\section{Concentrations of antifungal agents in foods}

Antifungal agents were detected in 1,819 (26.0\%) of the total of 7,005 food samples. The detection rate in imported foods was $27.7 \%$, and that in domestic foods was $7.0 \%$. The concentrations of each antifungal agent in foods are shown in Tables 2 to 5.

a) Diphenyl Diphenyl is allowed to be used on grapefruits, lemons, and oranges at a concentration of not more than $70 \mathrm{mg} / \mathrm{kg}^{7}$. Diphenyl was detected in $2(0.1 \%)$ out of 1,481 samples (Table 2$)$. The samples in which it was detected were from imported lemons (1 sample) and imported oranges (1 sample). The concentration of diphenyl in the one sample of lemons was $1.0 \mathrm{mg} / \mathrm{kg}$, and it was $1.0 \mathrm{mg} / \mathrm{kg}$ in the oranges. Diphenyl concentrations corresponded to $0.1 \%$ of the limit. The mean concentration in all tested lemons was $0.000476 \mathrm{mg} / \mathrm{kg}$, and it was $0.000331 \mathrm{mg} / \mathrm{kg}$ in the tested oranges, corresponding to $0.0007 \%$ and $0.0005 \%$, respectively, of the limit. No diphenyl was detected in grapefruits (306 samples), which is one of the foods in which diphenyl is allowed. The detection rate and the mean concentration of diphenyl in the present investigation based on the official inspection in 1998 were about $1 / 20$ and $1 / 100$ or less, respectively, of those in $1994^{12)}$. No diphenyl was detected in 475 samples in which the compound is not allowed to be used (nonpermissible foods), such as bananas (124 samples), nonpermissible fruits other than bananas (93 samples), nonalcoholic beverages (59 samples), and jam and marmalade (54 samples).

b) Imazalil Imazalil was detected in 889 of the 1,881 samples tested (47.3\%) (Table 3 ). The detection rates in citrus (except mandarin oranges) and bananas, in which imazalil is allowed to be used, were $66.4 \%$ and $4.5 \%$, respectively, and the mean concentrations in the samples in which it was detected were $1.33 \mathrm{mg} / \mathrm{kg}$ ( $26.7 \%$ of the limit) in citrus, and $0.33 \mathrm{mg} / \mathrm{kg}(16.4 \%$ of the limit) in bananas. The concentrations in all samples tested were calculated as $0.886 \mathrm{mg} / \mathrm{kg}$ in citrus and $0.015 \mathrm{mg} / \mathrm{kg}$ in bananas, corresponding to $17.7 \%$ and $0.7 \%$, respectively, of the allowable limits $(5.0 \mathrm{mg} / \mathrm{kg}$ for whole citrus and $2.0 \mathrm{mg} / \mathrm{kg}$ for whole bananas) $)^{7}$. Imazalil was also detected in 5 out of 54 samples of jam and 1 out of 1 sample of processed lemon peel. No 


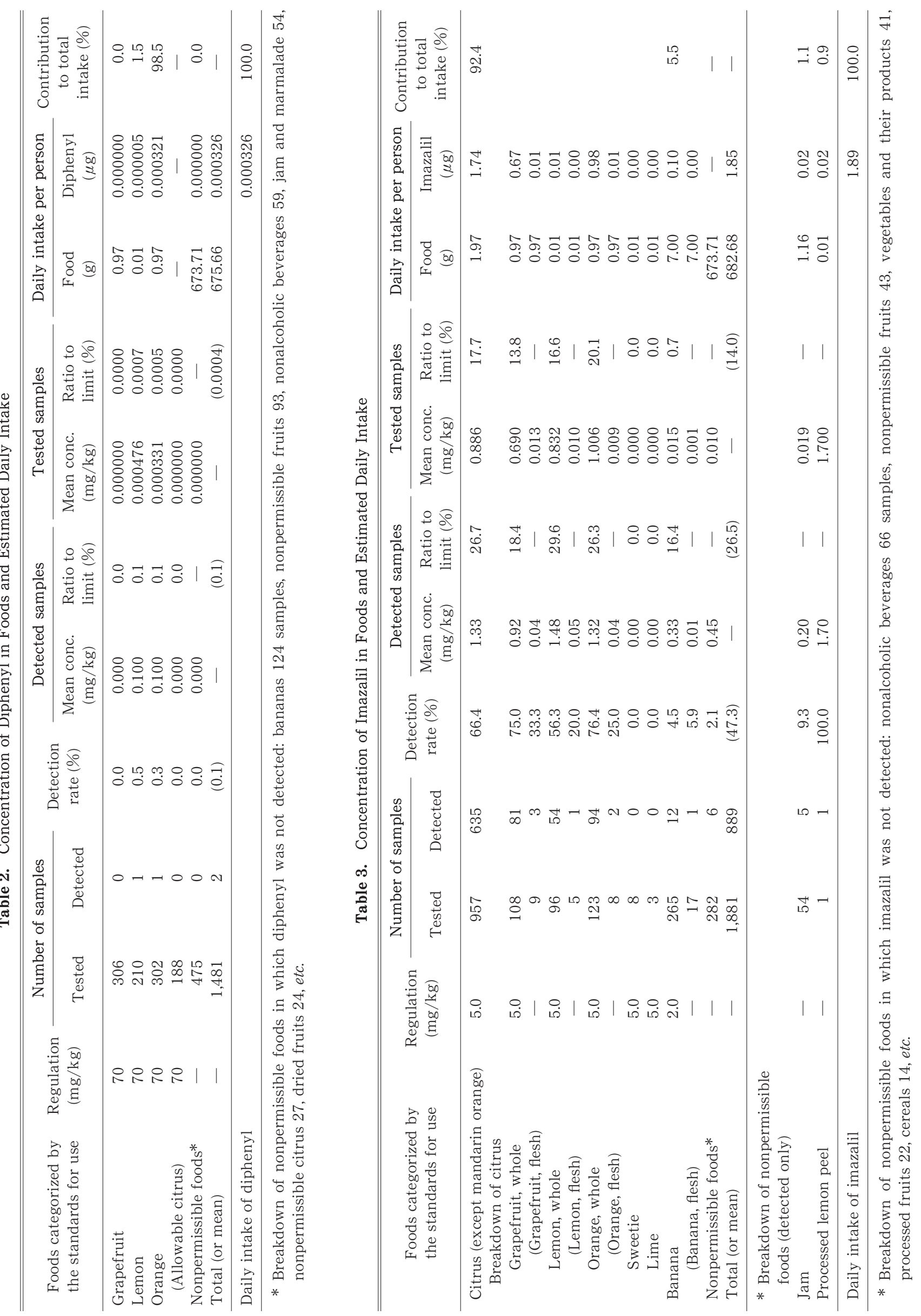




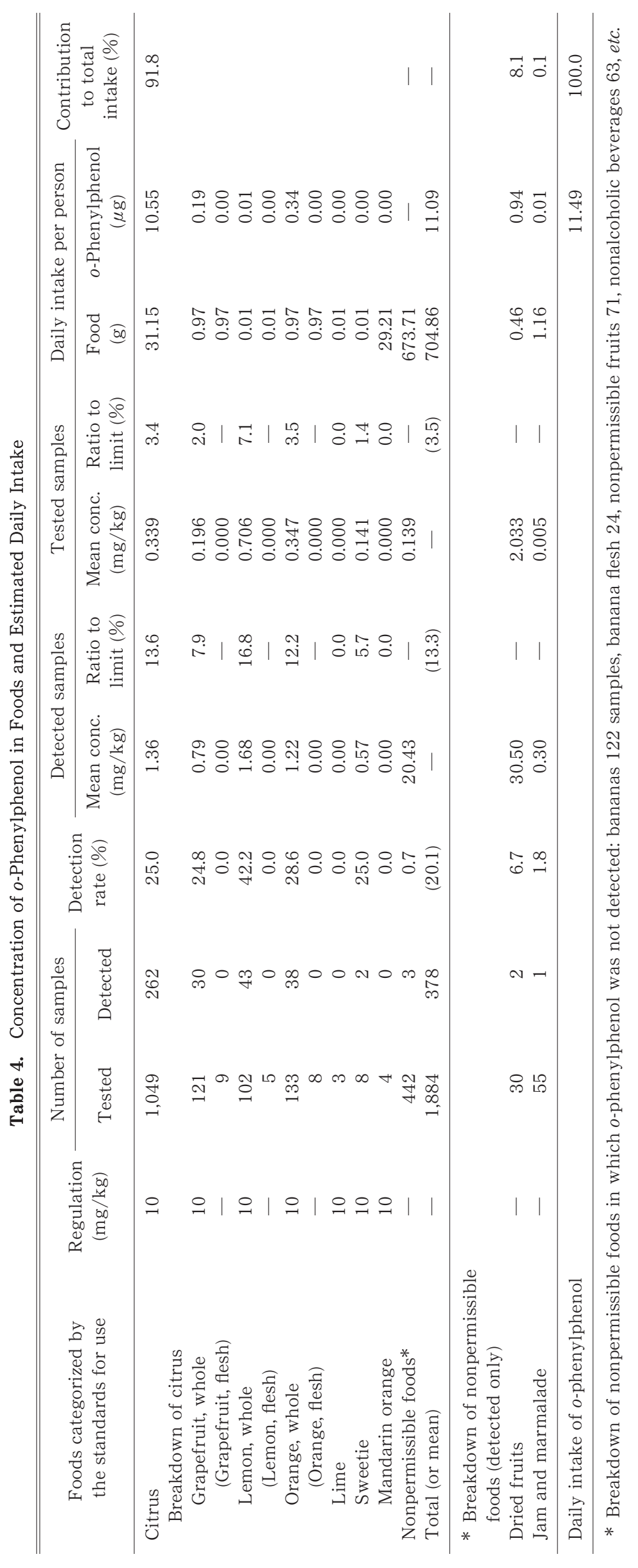




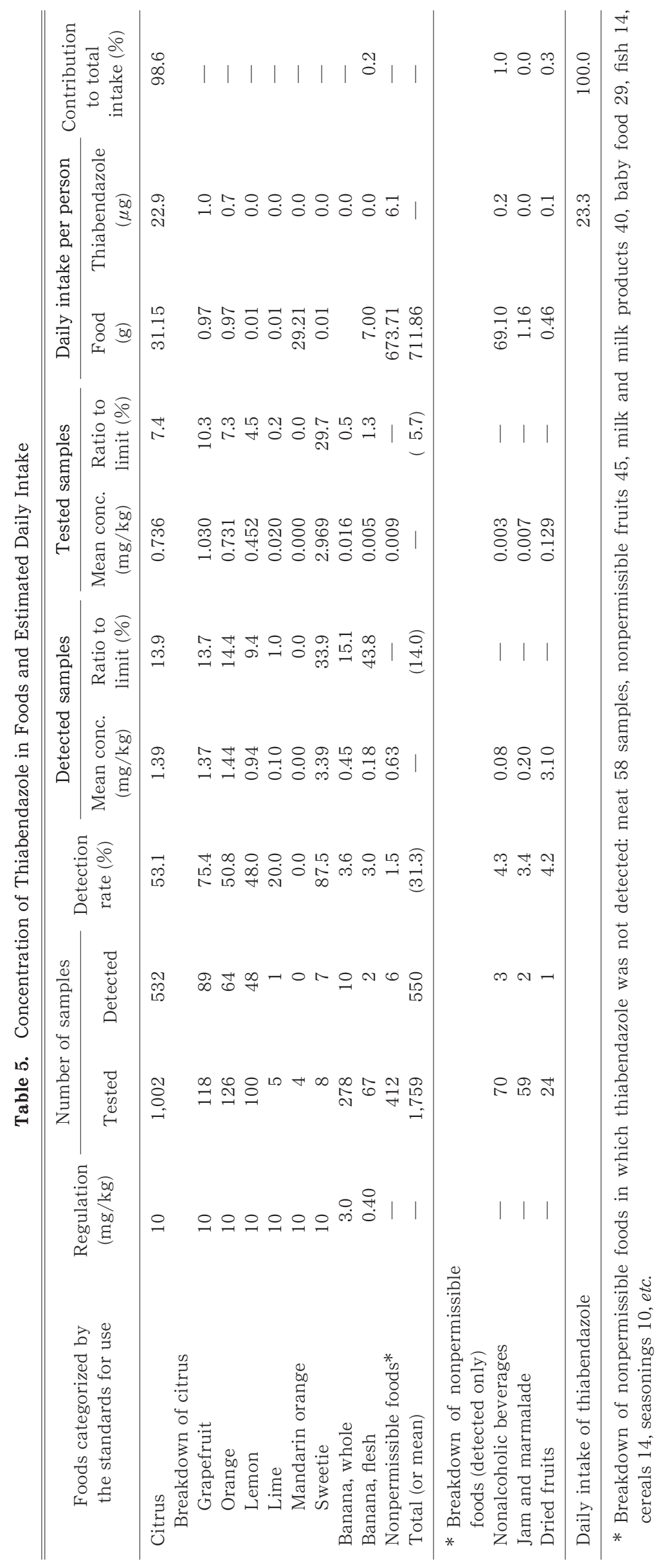


Table 6. Estimated Daily Intake of Antifungal Agents and Ratios to ADI

\begin{tabular}{|c|c|c|c|c|c|c|c|c|}
\hline \multirow[b]{2}{*}{$\begin{array}{l}\text { Antifungal agent } \\
\text { (Target year) }\end{array}$} & \multicolumn{2}{|c|}{ Present study } & \multicolumn{5}{|c|}{ Daily intake ( $\mu \mathrm{g} /$ person) in References } & \multirow[b]{2}{*}{$\begin{array}{l}\text { ADI }(\mu \mathrm{g}) \text { as } \\
50 \mathrm{~kg} \text { b.w. }\end{array}$} \\
\hline & $\begin{array}{c}\text { Daily intake } \\
\text { ( } \mu \mathrm{g} / \text { person }) \\
(1998)\end{array}$ & $\begin{array}{l}\text { Ratio to } \\
\text { ADI }(\%)\end{array}$ & $\begin{array}{l}\text { Japan*1 } \\
\text { (1996) }\end{array}$ & $\begin{array}{l}\text { Japan }^{* 2} \\
(1994)\end{array}$ & $\begin{array}{l}\text { Japan }^{* 3} \\
(1997)\end{array}$ & $\begin{array}{c}\text { Japan*4 } \\
(2000)\end{array}$ & $\begin{array}{c}\text { Finland*5 } \\
(1980)\end{array}$ & \\
\hline Diphenyl & 0.000326 & 0.000013 & 0.0395 & 2.6 & 0 & 0 & 14 & 2,500 \\
\hline Imazalil & 1.89 & 0.15 & 11.1 & 8.8 & 0 & 0 & 2.1 & 1,250 \\
\hline$o$-Phenylphenol & 11.5 & 0.12 & 8.97 & 14 & 0 & 0 & 7 & 10,000 \\
\hline Thiabendazole & 23.3 & 0.47 & 26.2 & 35 & 0.051 & 1.07 & 12 & 5,000 \\
\hline
\end{tabular}

*1: Based on the official inspection ${ }^{2)}$

$* 2$ : Based on the official inspection ${ }^{12)}$

*3: Based on the market basket method ${ }^{16)}$

*4: Based on the market basket method ${ }^{11}$

$*_{5}$. Based on the official analysis and data in journals ${ }^{15}$

imazalil was detected in nonalcoholic beverages (66 samples), nonpermissible fruits (43 samples), vegetables and their products (41 samples), and processed fruits (22 samples).

c) o-Phenylphenol o-Phenylphenol and sodium ophenylphenol are allowed to be used on citrus at the maximum level of $10 \mathrm{mg} / \mathrm{kg}$ as food additives in Japan, and the limits of these phenylphenols are regulated in terms of the total amount of $o$-phenylphenol ${ }^{7)}$ in the whole citrus body. o-Phenylphenol was detected in 378 (20.1\%) of the 1,884 samples tested (Table 4 ). The mean concentration in citrus tested was $0.339 \mathrm{mg} / \mathrm{kg}$ and was $3.4 \%$ of the limit, and the mean concentration in the samples in which it was detected was $1.36 \mathrm{mg} / \mathrm{kg}$, $13.6 \%$ of the limit. $o$-Phenylphenol was not detected in limes (3 samples) or mandarin oranges (4 samples), but was detected in 3 nonpermissible foods: 2 out of 30 samples of dried fruits and 1 out of 55 samples of jam and marmalade. No $o$-phenylphenol was detected in any other nonpermissible food samples (375 samples), including bananas and banana flesh (146 samples), nonpermissible fruits (71 samples), and nonalcoholic beverages (63 samples).

d) Thiabendazole Thiabendazole was detected in 550 of the 1,759 samples tested (31.3\%) (Table 5). The detection rate in citrus (1,002 samples) and whole bananas (278 samples), in both of which thiabendazole is allowed to be used, was 53.1\% (532 samples) and $3.6 \%$, (10 samples), respectively. The mean concentration in samples of citrus in which it was detected was $1.39 \mathrm{mg} / \mathrm{kg}$ (13.9\% of the limit, $10 \mathrm{mg} / \mathrm{kg})$, and in whole bananas it was $0.45 \mathrm{mg} / \mathrm{kg}$ (15.1\% of the limit, $3.0 \mathrm{mg}$ / $\mathrm{kg})$. The concentration in all samples tested was 0.736 $\mathrm{mg} / \mathrm{kg}$ in citrus and $0.016 \mathrm{mg} / \mathrm{kg}$ in whole bananas, corresponding to $7.4 \%$ and $0.5 \%$, respectively, of the allowable limits. The allowable limit of thiabendazole in banana flesh is $0.40 \mathrm{mg} / \mathrm{kg}$, and $0.18 \mathrm{mg} / \mathrm{kg}$ of thiabendazole was detected in 2 of the 67 samples of banana flesh. The concentration corresponded to $0.05 \mathrm{mg} / \mathrm{kg}$ in all tested samples. Thiabendazole was also detected in some nonpermissible foods (6 out of 412 samples): nonalcoholic beverages (3 out of 70 samples) at a concentration of $0.003 \mathrm{mg} / \mathrm{kg}$, jam and marmalade (2 out of 59 samples, $0.007 \mathrm{mg} / \mathrm{kg}$ ), and dried fruits (1 out of 24 samples, $0.129 \mathrm{mg} / \mathrm{kg}$ ). No thiabendazole was detected in other nonpermissible food samples, such as meat (58 samples), nonpermissible fruits (45 samples), and milk and milk products (40 samples).

\section{Estimation of the daily intake of antifungal agents per person}

The daily intake of antifungal agents was estimated based on both the concentrations of antifungal agents obtained in the present studies and daily consumption of foods estimated by the Ministry of Health and Welfare $^{11)}$. The daily intake of thiabendazole from bananas was estimated based on the concentration in flesh, because thiabendazole in bananas is regulated in both whole bananas $(3.0 \mathrm{mg} / \mathrm{kg})$ and flesh $(0.40 \mathrm{mg} / \mathrm{kg})$. The estimated daily intake of antifungal agents per person was as follows: diphenyl, $0.000326 \mu \mathrm{g}$; imazalil, $1.89 \mu \mathrm{g} ; o$-phenylphenol, $11.5 \mu \mathrm{g} ;$ and thiabendazole, $23.3 \mu \mathrm{g}$, corresponding to $0.000013 \%, 0.15 \%, 0.12 \%$, and $0.47 \%$, respectively, of their acceptable daily intakes (ADIs) ${ }^{13)},{ }^{14}$. The estimated daily intakes of antifungal agents, except diphenyl, were similar to the results obtained in the previous report ${ }^{2), 12)}$. The daily intake of diphenyl in the present study was $0.8 \%$ of the estimated daily intake in fiscal year $1996^{2)}$ and $0.01 \%$ of that in 1994 ${ }^{12)}$. The estimated daily intakes of antifungal agents based on the official inspection in fiscal year 1998 are summarized in Table 6 together with the results reported in the previous papers ${ }^{2), 12)}$, other reports $^{15), 16)}$, and the ADIs ${ }^{13), 14)}$.

\section{Discussion}

The mean concentrations of four antifungal agents, diphenyl, imazalil, o-phenylphenol, and thiabendazole, in foods and their estimated daily intake based on official inspections by local governments in Japan in fiscal year 1994 and 1996 have already been reported $^{2), 12)}$. The same investigation was repeated employing the same method, but using the results of official inspections in fiscal year 1998 instead. The estimated daily intake of these antifungal agents per person was $0.000326,1.89,11.5$, and $23.3 \mu \mathrm{g}$, respective- 
1y. These results were similar to those obtained in the previous reports ${ }^{2)}{ }^{12}$, except that the amount of diphenyl had decreased to $1 / 100-1 / 10,000$ in the present study. The use of diphenyl has decreased, and diphenyl may have been replaced with imazalil or thiabendazole, newly allowed antifungal agents in the 1990's.

The daily intake of these antifungal agents has been estimated in Finland ${ }^{15)}$ by using the official analytical results according to almost the same method as used in the present paper. The estimation was also carried out in Japan ${ }^{11,16)}$ by a market basket method. The present results for the estimated daily intake of the three antifungal agents other than diphenyl were closer to those in Finland than to those estimated by the market basket method in Japan.

The use of antifungal agents is limited in some specific fruits such as citrus and bananas. The present method is more effective in estimating the daily intake than the market basket method, because antifungal agents in citrus or bananas are diluted with other foods and water to prepare homogenates in the market basket method. One of the biggest advantages is that it is possible to detect and estimate the daily intake of antifungal agents by carry-over, such as those in dried fruits, jam, and marmalade.

The concentrations and estimated daily intakes of antifungal agents reported in the present paper include both over- and underestimation factors, but the values are more likely to be overestimated, as discussed in the previous papers ${ }^{2), 12)}$. The biggest overestimation factor may be that, with the exception of thiabendazole in bananas, the results were estimated based on whole fruits, including peel in citrus and bananas. The mean concentration of imazalil in the flesh of citrus was $1 / 50$ $-1 / 100$ of that in whole fruits and $1 / 15$ in bananas, and no $o$-phenylphenol was detected in the flesh of any citrus in the present study. The estimates of daily intake of antifungal agents determined with peel included are known to be 500 times higher than without their peel ${ }^{17)}$. The possibility of the underestimation was discussed in the previous paper ${ }^{2}$. When negative samples were presumed to contain the detection limits, the estimated daily intake of these antifungal agents increased to $10-30 \mu \mathrm{g} /$ person, although these daily intakes are still less than $1 \%$ of the ADI.

\section{Acknowledgments}

We are indebted to the Standards Division, Department of Food Sanitation, Ministry of Health, Labor, and Welfare (former Division of Food Chemistry, Ministry of Health and Welfare), and local governments for cooperating with this survey. This work was partly supported by "Health Science Research Grants, 2000 and 2001" from the Ministry of Health, Labor, and Welfare.

\section{References}

1) Ishiwata, H., Sugita, T., Kawasaki, Y., Takeda, Y., Yamada, T., Nishijima, M., Fukasawa, Y., Estimation of preservative concentrations in food and their daily intake based on official inspection results in Japan in fiscal year 1996. Shokuhin Eiseigaku Zasshi (J. Food Hyg. Soc. Japan), 40, 246-258 (1999).

2) Ishiwata, H., Sugita, T., Kawasaki, Y., Takeda, Y., Yamada, T., Nishijima, M., Fukasawa, Y., Estimation of antifungal agent concentrations allowed as food additives in food and their daily intake based on official inspection results in Japan in fiscal year 1996. Shokuhin Eiseigaku Zasshi (J. Food Hyg. Soc. Japan), 40, 407-416 (1999).

3) Ishiwata, H., Sugita, T., Kawasaki, Y., Takeda, Y., Yamada, T., Nishijima, M., Fukasawa, Y., Estimation of inorganic food additive (nitrite, nitrate, and sulfur dioxide) concentrations in foods and their daily intake based on official inspection results in Japan in fiscal year 1996. Shokuhin Eiseigaku Zasshi (J. Food Hyg. Soc. Japan), 41, 79-85 (2000).

4) Ishiwata, H., Fukushima, A., Abe, Y., Yamada T., Nishijima, M., Fukasawa, Y., Estimation of BHA, BHT, propylene glycol, and sodium saccharin concentrations in foods and their daily intake based on official inspection results in Japan in fiscal year 1996. Shokuhin Eiseigaku Zasshi (J. Food Hyg. Soc. Japan), 41, 86-93 (2000).

5) Ishiwata, H., Nishijima, M., Fukasawa, Y., Estimation of preservative concentrations in foods and their daily intake based on official inspection results in Japan in fiscal year 1998. Shokuhin Eiseigaku Zasshi (J. Food Hyg. Soc. Japan), 42, 404-412 (2001).

6) Notification Ei-Ka No. 48 (September 10, 1999), "Inspection Results of Food Additives in Foods (request)." Director of the Division of Food Chemistry, Ministry of Health and Welfare, Japan.

7) Japan's Specifications and Standards for Food Additives, 7th Ed., English version, 2000, p. 335-360, Ministry of Health and Welfare, Japan.

8) Environmental Health Bureau, Ministry of Health and Welfare, Japan, supervised. "Shokuhin Kensa ShishinShokuhinchu No Shokuhintenkabustu Bunsekihou (Guide for Food Sanitation Inspection-Analytical methods for food additives in foods)", 1989, p. 89-102, Tokyo, Japan Food Hygiene Association.

9) Environmental Health Bureau, Ministry of Health and Welfare, Japan, supervised, "Shokuhin Kensa ShishinShokuhinchu No Shokuhintenkabustu Bunsekihou (Guide for Food Sanitation Inspection, Supplement II,Analytical methods for food additives in foods)", 1996, p. 299-302, Tokyo, Japan Food Hygiene Association.

10) Japan Food Additives Association, ed., "Shokuhin No Han-i Gaido (Guide for categorization of food)", Tokyo, Japan Food Additives Association, 1995.

11) Food Sanitation Investigation Council, "Report on the inspection of the daily intake of food additives (Shokuhin Tenkabutsu Ichinichi Sesshuryou Soutenken Chousa No Jisshi)", December 1, 2000.

12) Ishiwata, H., Nishijima, M., Fukasawa, Y., Ito, Y., Yamada, T., Evaluation of the contents of antifungal agents allowed as food additives in foods and the daily intake deduced from the results of the official inspection in Japan in fiscal year 1994. Shokuhin Eiseigaku Zasshi (J. Food Hyg. Soc. Japan), 38, 296-306 (1997).

13) Japan Food Additives Association, ed., "Food additives manual", Tokyo, Japan Food Additives Association, 2001, p. 292-338.

14) Food Sanitation Council, Japan, "Houkokusho (Report) No. 29", 1992.

15) Penttilä, P.-L., Salminen, S., Niemi, E., Estimation on the 
intake of food additives in Finland. Z. Lebensm. Unters. Forsch., 186, 11-15 (1988).

16) Investigation Group of the Daily Intake of Food Additives in Japan, "Heisei 9 Nendo Nihonjin Ni Okeru Shokuhintenkabutu No Ichinichi Sesshuryou Chousa (Daily intake of food additives in Japanese)", 1997, Heisei 9
Nendo Kousei Kagaku Kenkyuu Houkokusho (Report of the Health Sciences Research Grants, 1997).

17) Isshiki, K., Tsumura, S., Watanabe, T., Dietary intake of fungicides and piperonyl butoxide. Shokuhin Eiseigaku Zasshi (J. Food Hyg. Soc. Japan), 24, 344-349 (1983). 